\title{
Taller Jóvenes Investigadores Andinos sobre la vulnerabilidad urbana
}

La Paz, 3-7 de setiembre de 2007

\section{Robert D'Ercole}

\section{CpenEdition}

Journals

Edición electrónica

URL: http://journals.openedition.org/bifea/3765

DOI: 10.4000/bifea.3765

ISSN: 2076-5827

\section{Editor}

Institut Français d'Études Andines

\section{Edición impresa}

Fecha de publicación: 1 diciembre 2007

Paginación: 462-464

ISSN: 0303-7495

\section{Referencia electrónica}

Robert D'Ercole, «Taller Jóvenes Investigadores Andinos sobre la vulnerabilidad urbana », Bulletin de I'Institut français d'études andines [En línea], 36 (3) | 2007, Publicado el 01 junio 2008, consultado el 12 diciembre 2020. URL : http://journals.openedition.org/bifea/3765 ; DOI : https://doi.org/10.4000/bifea. 3765

Les contenus du Bulletin de l'Institut français d'études andines sont mis à disposition selon les termes de la licence Creative Commons Attribution - Pas d'Utilisation Commerciale - Pas de Modification 4.0 International. 


\section{TALLER JÓVENES INVESTIGADORES ANDINOS SOBRE LA VULNERABILIDAD URBANA}

La Paz, 3-7 de setiembre de 2007

En razón de su contexto geodinámico y climático, y de una urbanización a menudo mal controlada, Bolivia, Perú y Ecuador están confrontados a un gran número de riesgos de origen natural y humano. Como lo ha demostrado el sismo de Pisco del 15 de agosto de 2007, estos riesgos se convierten frecuentemente en catástrofes que afectan duramente a la población, a las infraestructuras, a los bienes públicos y privados, a la economía de esos países y, por consiguiente, a las condiciones mismas de su desarrollo. Estos riesgos y catástrofes conciernen más particularmente a los medios urbanos de estos tres países. Estos presentan vulnerabilidades ligadas a su exposición a un gran número de amenazas 
de origen natural, pero también a su capacidad intrínseca en aumentar los efectos de estas amenazas y a suscitar nuevas, de carácter netamente antrópico. Para desarrollar una reflexión científica sobre estos temas, la representación del IRD en Bolivia ha acogido en La Paz, del 3 al 7 de setiembre de 2007, el primer taller «Jóvenes investigadores andinos sobre la vulnerabilidad urbana».

Este taller ha sido organizado por el equipo de investigación PACIVUR (Programa Andino de Capacitación y de Investigación sobre la Vulnerabilidad y los Riesgos en medio urbano) del laboratorio UR 029 Medio Ambiente Urbano del IRD, con el auspicio del IFEA (Instituto Francés de Estudios Andinos), de la Cooperación Regional Francesa para los Países Andinos y de la Embajada de Francia en Bolivia. Su objetivo era reunir a jóvenes investigadores que trabajan bajo la supervisión del IRD, provenientes de los tres países andinos cubiertos por el programa PACIVUR (Bolivia, Ecuador, Perú), y que actualmente efectúan investigaciones en torno al tema de la vulnerabilidad en medio urbano. Además de los nueve jóvenes investigadores andinos, han participado igualmente en este taller tres profesores-investigadores de universidades asociadas (Bolivia, Ecuador, Perú), dos profesores-investigadores de universidades chilenas invitados como observadores, un profesor-investigador de una universidad francesa que aportó una visión exterior (Patrick Pigeon, profesor de la Universidad de Saboya y especialista de la vulnerabilidad urbana en Europa y Asia), un miembro del Joven Equipo de investigación ecuatoriano PAUD (Por el ambiente Urbano y Desarrollo) que realiza una tesis de doctorado financiada por el IRD, un estudiante francés de maestría de geografía (Universidad de Saboya) acogido por el Joven equipo PAUD, y dos miembros del equipo de investigación PACIVUR (Robert d'Ercole y Sébastien Hardy).

Los diecinueve participantes, principalmente geógrafos, hicieron un balance de las investigaciones efectuadas en torno a la vulnerabilidad y a los riesgos en medio urbano en los países del programa PACIVUR y presentaron sus estudios de investigación en curso referentes a los diferentes aspectos de la vulnerabilidad urbana (vulnerabilidad territorial, social e institucional, vulnerabilidad ligada a la falta de accesibilidad, transmisión de las vulnerabilidades, espacios de riesgo, y espacios generadores de vulnerabilidad, escalas de análisis de las vulnerabilidades, etc.). Ellos tuvieron reuniones con los encargados del manejo de riesgos de las municipalidades de La Paz y de El Alto y fueron sobre el terreno para descubrir las problemáticas propias de las vulnerabilidades y riesgos de los territorios paceños. Los participantes han aprendido a conocerse mejor a través de las diferentes actividades comunes, en particular las salidas de terreno y los intercambios científicos y de experiencias, tanto a nivel conceptual como metodológico. De esta manera, están en condiciones, en un futuro cercano, de desarrollar actividades de investigación en común en contextos diferentes. Uno de los objetivos del programa PACIVUR consiste en efecto en implementar y desarrollar una red de instituciones y de jóvenes investigadores que trabajan sobre la vulnerabilidad y los riesgos en medio urbano en los países de la región andina y articular de esta manera los estudios de investigación: definiendo líneas de investigación comunes, estableciendo puntos de comparación, adoptando un punto de vista pluridisciplinario, etc.

El taller ha puesto en evidencia la debilidad de la investigación sobre la vulnerabilidad urbana en los países andinos: aquí la investigación está esencialmente centrada en las amenazas o sobre el aspecto ingeniería de la vulnerabilidad (vulnerabilidad de las construcciones respecto de los sismos, por ejemplo). Dicho esto, según los países se han observado diferencias de avance de la investigación sobre la vulnerabilidad urbana: el Ecuador (Quito en particular, a raíz de los estudios realizados entre 1999 y 2004 en el marco de la colaboración entre el IRD y la Municipalidad) está más adelantado que el Perú y sobre todo que Bolivia. También se ha constatado que la manifestación de los riesgos en las 
ciudades andinas depende no tanto de la ausencia de investigación de soluciones, técnicas en su mayoría, sino de las dificultades en incorporar la vulnerabilidad bajo sus diversas formas y de manera global en la gestión urbana. Eso constatado, los participantes del taller sugirieron desarrollar las investigaciones sobre la vulnerabilidad urbana en colaboración con los encargados de este tema en las municipalidades y a partir de situaciones concretas, lo que supone un alto componente de trabajo de campo y por consiguiente salir de un marco a menudo demasiado teórico. Las tres capitales andinas se han visto recientemente concernidas por crisis generalizadas ligadas a erupciones volcánicas (Quito en 1999, y en 2002), inundaciones (La Paz en 2002) y terremotos (Lima, 2007). También, el análisis posterior a estas crisis es un ejemplo de investigación considerada productiva, susceptible de sensibilizar tanto a los decididores como a la población, y aportar herramientas de ayuda a la decisión para el manejo de las futuras crisis. El análisis de las políticas de manejo de riesgos constituye otra entrada para investigaciones sobre la vulnerabilidad urbana. Se trata además de centrar estas investigaciones en la concretización sobre el terreno de estas políticas (por ejemplo en materia de acondicionamiento en las zonas de riesgos). Este tipo de enfoque referente al análisis, desde el terreno, de las situaciones de crisis o de las políticas de manejo de riesgos, permite identificar diversos intereses mayores territoriales y diversas formas de vulnerabilidad, de relacionar estas últimas entre ellas y de desembocar en una lectura sistémica de la vulnerabilidad urbana.

Basándose en el balance muy positivo de esta primera experiencia, los participantes han previsto organizar en 2008, en Quito, un segundo taller Jóvenes investigadores andinos sobre la vulnerabilidad urbana («PACIVUR Jóvenes», 2aㅡ edición). Allí se tratará de hacer un balance sobre el avance de las investigaciones que integrarán en particular los preconizados enfoques «terreno». También, la intención es de abrirse más ampliamente a otras disciplinas además de la geografía. En espera de este segundo encuentro, los participantes del taller han decidido poner en línea y alimentar una base de datos bibliográfica sobre la investigación en torno a la vulnerabilidad en medio urbano en los países andinos. Podrán acceder a esta base los miembros del equipo «PACIVUR Jóvenes», así como cualquier persona interesada en el tema. Paralelamente y de manera progresiva, los equipos de jóvenes investigadores elaborarán afiches referentes a las investigaciones sobre la vulnerabilidad en medio urbano, los mismos que circularán dentro de los países andinos, y estarán dirigidos a un amplio público (universidades, municipalidades, etc.). No cabe duda que el IRD y sus contrapartes, entre las cuales el IFEA y la Cooperación Regional Francesa para los Países Andinos, apoyarán nuevamente estas acciones de capacitación y de difusión científica que facilitarán la emergencia y el reconocimiento de jóvenes investigadores en un campo de investigación particularmente útil para el manejo de los riesgos y de las crisis en las ciudades andinas.

Contactos:

Robert D'Ercole: robert.dercole@ird.fr

Sébastien Hardy: sebastien.hardy@ird.fn 